\title{
Bio-inspired design of ice-retardant devices based on benthic marine invertebrates: the effect of surface texture
}

Growth of ice on surfaces poses a challenge for both organisms and for devices that come into contact with liquids below the freezing point. Resistance of some organisms to ice formation and growth, either in subtidal environments (e.g. Antarctic anchor ice), or in environments with moisture and cold air (e.g. plants, intertidal) begs examination of how this is accomplished. Several factors may be important in promoting or mitigating ice formation. As a start, here we examine the effect of surface texture alone. We tested four candidate surfaces, inspired by hard-shelled marine invertebrates and constructed using a threedimensional printing process. We examined sub-polar marine organisms to develop sample textures and screened them for ice formation and accretion in submerged conditions using previous methods for comparison to data for Antarctic organisms. The sub-polar organisms tested were all found to form ice readily. We also screened artificial 3-D printed samples using the same previous methods, and developed a new test to examine ice formation from surface droplets as might be encountered in environments with moist, cold air. Despite limitations inherent to our techniques, it appears surface texture plays only a small role in delaying the onset of ice formation: a stripe feature (corresponding to patterning found on valves of blue mussels, Mytilus edulis, or on the spines of the Antarctic sea urchin Sterechinus neumayeri slowed ice formation an average of $25 \%$ compared to a grid feature (corresponding to patterning found on sub-polar butterclams, Saxidomas nuttalli. The geometric dimensions of the features have only a small ( $6 \%)$ effect on ice formation. Surface texture affects ice formation, but does not explain by itself the large variation in ice formation and speciesspecific ice resistance observed in other work. This suggests future examination of other factors, such as material elastic properties and surface coatings, and their interaction with 


\section{surface pattern.}

PeerJ reviewing PDF | (v2014:06:2317:2:0:NEW 23 Aug 2014) 


\title{
Bio-inspired design of ice-retardant devices based on benthic marine invertebrates: the effect of surface texture
}

\author{
Homayun Mehrabani $^{1}$, Neil Ray ${ }^{1,4}$, Kyle Tse $^{2}$, and Dennis Evangelista*3,5 \\ ${ }^{1}$ Department of Bioengineering, University of California, Berkeley, CA 94720-1762, USA \\ ${ }^{2}$ Department of Mechanical Engineering, University of California, Berkeley, CA \\ 94720-1740, USA \\ ${ }^{3}$ Department of Integrative Biology, University of California, Berkeley, CA 94720-3140, \\ USA \\ ${ }^{4}$ Current address: Duke University School of Medicine, Durham, NC 27710, USA \\ ${ }^{5}$ Current address: Department of Biology, University of North Carolina at Chapel Hill, \\ NC 27510-3280, USA
}

\begin{abstract}
Growth of ice on surfaces poses a challenge for both organisms and for devices that come into contact with liquids below the freezing point. Resistance of some organisms to ice formation and growth, either in subtidal environments (e.g. Antarctic anchor ice), or in environments with moisture and cold air (e.g. plants, intertidal) begs examination of how this is accomplished. Several factors may be important in promoting or mitigating ice formation. As a start, here we examine the effect of surface texture alone. We tested four candidate surfaces, inspired by hard-shelled marine invertebrates and constructed using a three-dimensional printing process. We examined sub-polar marine organisms to develop sample textures and screened them for ice formation and accretion in submerged conditions using previous methods for comparison to data for Antarctic organisms. The sub-polar organisms tested were all found to form ice readily. We also screened artificial 3-D printed samples using the same previous methods, and developed a new test to examine ice formation from surface droplets as might be encountered in environments with moist, cold air. Despite limitations inherent to our techniques, it appears surface texture plays only a small role in delaying the onset of ice formation: a stripe feature (corresponding to patterning found on valves of blue mussels, Mytilus edulis, or on the spines of the Antarctic sea urchin Sterechinus neumayeri) slowed ice formation an average of $25 \%$ compared to a grid feature (corresponding to patterning found on sub-polar butterclams, Saxidomas nuttalli). The geometric dimensions of the features have only a small $(\sim 6 \%)$ effect on ice formation. Surface texture affects ice formation, but does not explain by itself the large variation in ice formation and species-specific ice resistance observed in other work. This suggests future examination of other factors, such as material elastic properties and surface coatings, and their interaction with surface pattern.
\end{abstract}

Keywords: ice, invertebrates, Antarctica, benthic, texture

\section{INTRODUCTION}

Ice nucleation remains a serious issue for many industrial applications where spray, contact with, or submersion in liquids in sub-freezing point environments is inevitable. Piping systems, ship hulls, airplane wings, and road surfaces are all situations where the accumulation of ice can compromise safety

5 or strength, reduce friction available for traction, impose additional weight, reduce stability, or alter aerodynamic or hydraulic performance. Though methods of actively removing ice after its formation (chemicals (Hassan et al., 2002), rubber mallets, inflatable boots, heating cables, bleed air, geothermal (Makkonen et al., 2001) or microwave heating (Hansman, 1982) de-icing systems) have been developed to varying degrees of effectiveness, prevention using passive means is preferable (Hassan et al., 2002).

*author for correspondence: devange177b@gmail.com 
In both plants and animals, previous work has shown that ice formation can adversely affect physiology and function or present severe ecomechanical (Wainwright and Reilly, 1994; Carrington, 2002; Denny and Helmuth, 2009; Denny and Gaylord, 2010) challenges, in which mechanics, physiology, environmental physics and ecology are strongly linked, that are likely to be selective (Gusta et al., 2004; Wisniewski et al., 2002; Denny et al., 2011). Biological systems may have evolved features to ameliorate the effects of ice that could be copied in engineered devices. For example, (Gusta et al., 2004) studied ice nucleation within plant leaves and the effects of anti-freeze proteins in systems with internal flow, finding differences between species and between different acclimation treatments. While such observations are important, they may not be of help in larger scale devices where it is undesirable to alter chemistry; furthermore, extrinsic sources of ice nucleation may be just as damaging (Wisniewski et al., 2002). As another example, 2011; Mager et al. 2013), during supercooled conditions, anchor ice readily forms on some organisms (the sponges Homaxinella balfourensis and Suberites caminatus), while others are resistant (the rubbery soft coral Alcyonium antarcticum, the sea urchin Sterechinus neumayeri, the sponge Mycale acerata, and the sea star Odontaster validus). Accretion of ice can interfere with physiological function and the resulting positive buoyancy can cause removal; as a result, different suceptibility to ice formation affects the community makeup and local ecology (Dayton et al., 1969, 1970; Dayton, 1989; Pearse et al., 1991; Gutt, 2001; Denny et al., 2011; Mager et al., 2013). Denny et al. (Denny et al., 2011) did not test the mechanical determinants of the differences in ice formation, though they pointed out the presence of mucus (in Mycale) in contrast with the others, as well as the difference between spongy or rubbery

organisms and those with hard surfaces like the urchins and sea stars. (Denny et al., 2011) also did not provide contrast with sub-polar organisms.

There are clearly many variables that can affect the formation and adhesion of ice. Biological systems may make use of many mechanisms of ice inhibition concurrently and may exploit any or all of the following (Gutt, 2001; Denny et al., 2011; Gusta et al., 2004; Wisniewski et al., 2002): shape and mechanical pattern, multi-scale features, internal and surface chemistry, coatings, active coatings like cilia, variation in material properties, animal behavior. Unfortunately, not all techniques used in living systems are amenable to large-scale engineering application with current technology. While it is tempting to model everything to the finest scale possible, it is important also to determine the simplest treatment that might work. Can we narrow the variables of interest, to learn about both the biology and potential applications?

We hypothesized that surface texture provides protection from ice formation, i.e. for purposes of manufacturability, an attractive engineering solution is one using mechanical patterning alone. To address if this is possible, we tested four candidate artificial surface textures (grid, valley, cone, stripes) inspired by benthic invertebrates (Saxidomas nuttalli, Crassostrea gigas, Pisaster ochraceus, and Mytilus edulis, (material, stiffness, density, thermal conductivity, specific heat, and surface wetting) held constant. To examine sensitivity, a range of surface parameters (feature spacing and height), bounding the range seen in organisms, was tested. Tests included both the ice formation test of (Denny et al., 2011) and a new test to examine ice formation in cold air. Such testing is conveniently also the first step in dissecting the underlying biomechanical causes of inter-species variation described in (Denny et al., 2011); furthermore, it allows comparison between organisms with similar surfaces but different latitudinal distribution (polar versus sub-polar).

\section{METHODS AND MATERIALS}

\section{Biological samples and ice formation test}

We obtained samples of the hard external surfaces of live sub-polar marine invertebrates from a local 55 grocery store (Ranch 99, El Cerrito, CA) and from material leftover from undergraduate biology teaching labs, including three bivalve mollusks, butterclams (Saxidomas nuttalli), blue mussels (Mytilus edulis), and Pacific oysters (Crassostrea gigas), and one echinoderm, ochre sea star (Pisaster ochraceus), (Figure 1). The material was subjected to the ice formation test of (Denny et al., 2011), to contrast it with the Antarctic species reported by Denny et al..

Biological samples ( $<2 \mathrm{~cm}$ maximum dimension) were placed in open, unstirred $250 \mathrm{~mL}$ polypropylene tripour beakers and filled with $150 \mathrm{~mL}$ of $32 \mathrm{psu}$ artificial seawater (Instant Ocean, Blacksburg, VA). Samples were placed so that the outer side was facing up. Both sample and seawater were initially at $4{ }^{\circ} \mathrm{C}$. Multiple beakers were placed on a fiberglass tray which was then placed in a $-20^{\circ} \mathrm{C}$ walk-in freezer, 

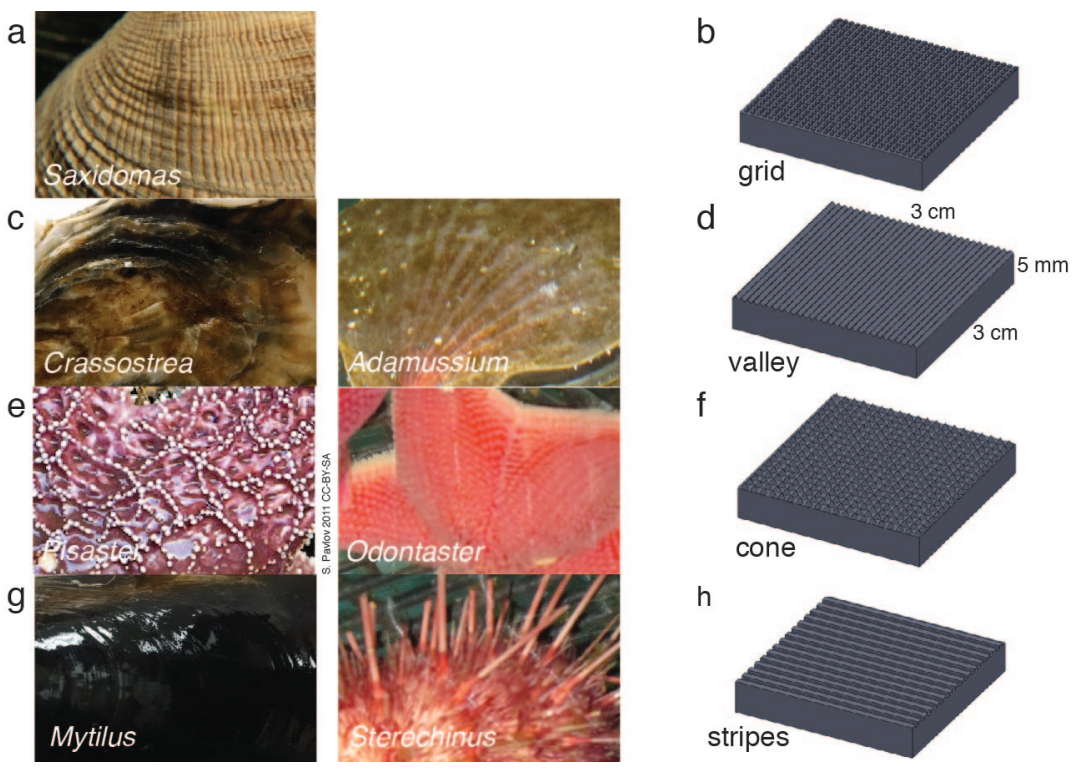

Figure 1. Biological inspiration and surface fabrication. (a-b) Saxidomas nuttalli and grid texture; (c-d) Crassostrea gigas and valley texture, similar to the Antarctic scallop Adamussium colbecki; (e-f) Pisaster ochraceus (Pavlov, 2011) and cone texture, similar to the Antarctic sea star Odontaster validus; (g-h) Crassostrea gigas and striped texture, similar to the patterning on spines of the Antarctic urchin Sterechinus neumayeri. Photos scaled to approximately $3 \mathrm{~cm}$ width.

away from overhead fans and partially shielded by surrounding cardboard to the side and above. Beakers were observed for ice formation on the sample within the first $10 \mathrm{~min}$. As in (Denny et al., 2011), five beakers of each sample type were placed randomly on the fiberglass tray alongside five empty beakers with artificial seawater only, as controls. Additional trays were used to obtain three replicates, each of five beakers, for the four sample types and the control. As in (Denny et al., 2011), ice was always observed forming on the surface edges; the beaker was scored as a positive only if ice was also observed forming on the submerged surface of the sample prior to the beaker freezing completely from above (typically within $10 \mathrm{~min}$ ); this is the same criterion as (Denny et al., 2011).

The presence or absence of visible ice growth originating on the sample provides a gross measure of propensity to form anchor ice (Denny et al., 2011), subject to some caveats we provide in the discussion. Also, unlike (Denny et al., 2011), we used artificial seawater rather than McMurdo seawater drawn from the Crary Lab seawater system; we also use an initial temperature of $4{ }^{\circ} \mathrm{C}$ rather than $1{ }^{\circ} \mathrm{C}$; these were addressed by the artificial seawater controls used.

\section{Biological inspiration and surface fabrication}

Biological samples were observed under a 10x dissecting microscope, measured and sketched. To exaggerate specific physical properties in repeatable patterns to observe phenomena that are a result of surface texture alone, we used a three dimensional printing (3DP) process to create engineered samples mimicking the biological samples. Samples measured $0.03 \mathrm{~m} \times 0.03 \mathrm{~m} \times 0.005 \mathrm{~m}$ overall and included patterning of four textures: grid, valley, cone, and stripes (Figure 1). The textures corresponded to Saxidomas, Crassostrea, Pisaster, and Crassostrea respectively. The cone texture is also similar to the Antarctic sea star Odontaster, while the striped texture, consisting of square-edged ridges, is similar to patterning observed on the spines of the Antarctic urchin Sterechinus; both are known to be resistant to ice formation (Denny et al., 2011). The valley texture, consisting of triangle-shaped ridges, is similar to the corrugations on the Antarctic swimming scallop Adamussium colbecki, although such corrugations are likely linked to weight reduction needed in order to swim (Denny and Miller, 2006), and the presence of epibionts may alter that organism's propensity to form ice.

The observed textures (Figure 1) ranged from $0.25 \mathrm{~mm}$ to $0.5 \mathrm{~mm}$ high. Features were spaced approximately $0.5 \mathrm{~mm}$ to $0.75 \mathrm{~mm}$ for the grid-like texture on Saxidomas; approximately $1 \mathrm{~mm}$ to $3 \mathrm{~mm}$ 
for the groove-like/valley texture on Crassostrea; $0.5 \mathrm{~mm}$ to $4 \mathrm{~mm}$ for the cone texture of Pisaster; and $0.5 \mathrm{~mm}$ for the stripe texture on Mytilus. These measurements were used in designing the textures: for initial screening, a height of $0.5 \mathrm{~mm}$ was used, with pattern spacing set at $0.5 \mathrm{~mm}$ for grid, valley, and stripes and $1.5 \mathrm{~mm}$ for cone.

We designed the textures using two solid-modeling programs: Solidworks (Dassault Systems, Waltham, MA) and Blender (Blender Foundation, Amsterdam, Netherlands). Solid models were used to prepare stereolithography (STL) files that were printed in ABS plastic using a ProJet 3000 3D printer (3D Systems, Rose Hill, SC). Newly printed samples were cleaned of support material by gentle heating and use of an $80^{\circ} \mathrm{C}$ sonicating warm-oil bath, then washed thoroughly with detergent before testing.

\section{Ice formation test of sample plates}

As with the biological samples, we tested the four sample plates using the ice formation test of (Denny et al., 2011) (Figure 2(a)). Based on the results of this test, the best-performing and worst-performing textures were selected for further optimization of the surface parameters (pattern spacing and height), to examine sensitivity. All sample plates were found to exhibit ice formation during the test period and the time to initial observation of ice formation was recorded. Also, since all sample plates exhibited ice formation, further examination of pattern sensitivity used a new test to more closely examine the freeze time as well as ice formation in intertidal or terrestrial cases.

\section{Droplet tests of sample plates}

110 An additional series of sample plates based on the best-performing and worst-performing textures from the ice formation test was prepared, varying the pattern spacing from $0.5 \mathrm{~mm}$ to $4 \mathrm{~mm}$ and pattern height from $0.25 \mathrm{~mm}$ to $1 \mathrm{~mm}$. In addition, several untextured control plates were also prepared as controls (STL files available for download). Plates were dried and stored in $4{ }^{\circ} \mathrm{C}$ walk-in freezer overnight to provide isothermal starting conditions. Plates were placed randomly in rows on a plastic tray for testing. Five the center (Figure 2(b-c)). For the droplet test, a small amount of red food coloring (Safeway, Pleasanton, CA) was used to tint the seawater to ease viewing of the end of freezing. The plates were then placed in a $-20^{\circ} \mathrm{C}$ freezer on a flat surface away from overhead fans and observed during freezing. In addition to visual observation of samples with the naked eye, a digital video camera (Hewlett Packard, Palo Alto, CA) 20 was used to obtain time lapse images at 1 frame $^{-1}$ (example video available for download). Samples were observed over $30 \mathrm{~min}$ or until all of the samples froze. Samples were classified as frozen once the droplet turned from a slight red tint to opaque white (Figure 2(b)). The resulting freeze times were recorded and analyzed in R (R Core Team, 2014). For the results presented below, freeze times for a given test were normalized by the mean freeze time for the untextured control plates in the test.

\section{RESULTS}

\section{Ice formation test for biological samples and sample plates}

Unlike in Antarctic species tested in (Denny et al., 2011), all sub-polar biological samples we tested (hard external surfaces of Saxidomas nuttalli, Crassostrea gigas, Pisaster ochraceus, and Mytilus edulis) initiated ice formation during the ice formation test (Figure 3). This is discussed further below. For all original data for Antarctic species from (Denny et al., 2011, fig 3), normalized by the number of beakers (5) in each test.

All sample plates tested in the submerged ice formation test of (Denny et al., 2011) also initiated ice formation, however, there were broad differences in freeze time between the textures (ANOVA, $P=0.019$, Figure 4). The best-performing texture (stripes) increased the time to ice formation relative to the worst-performing texture (grid), by $25 \%$. On the other hand, wetted surface area did not appear to affect the freeze time (linear regression, $P=0.223$, Table 1 ).

\section{Droplet test and sensitivity of freeze time to pattern spacing}

Within both the best-performing texture (stripes) and the worst-performing texture (grid), the pattern

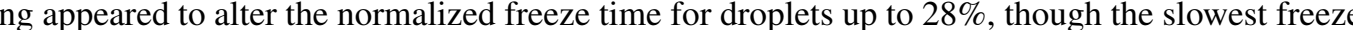
times were only delayed about $6 \%$ relative to the untextured control (Figure 5). Given a texture, there appears to be a (weakly) optimal feature spacing (ANOVA, $P=0.0004$ for spacing, $P=0.0389$ for 


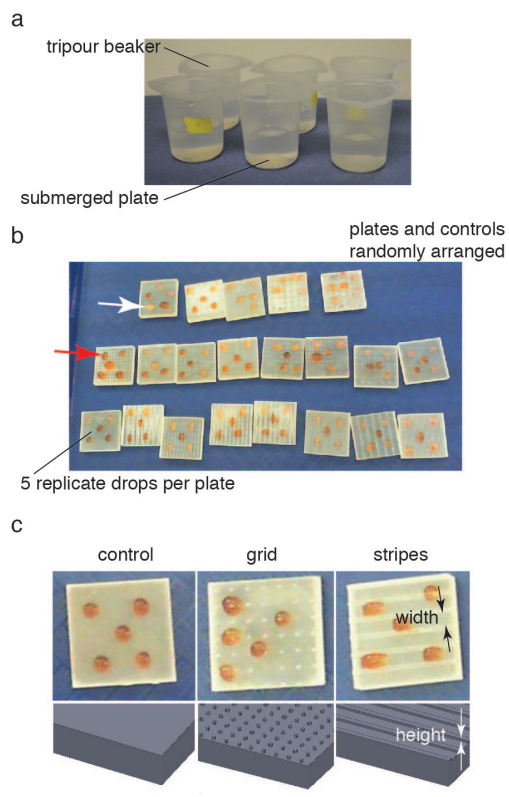

Figure 2. (a) Submerged ice formation test from (Denny et al., 2011). Plates were placed in $250 \mathrm{~mL}$ beakers and watched for ice formation in a $-20^{\circ} \mathrm{C}$ walk-in freezer. (b) Droplet test to test for ice formation in cold air (intertidal or terrestrial case). Plates and controls were randomly arranged on a tray in the same $-20^{\circ} \mathrm{C}$ freezer. Droplet freezing was identified by color shift from red (middle arrow; contrast agent red food coloring added) to white (upper arrow). Plates $0.03 \mathrm{~m}$ square. (c) Textures and control used during droplet test. Feature width and height varied between $0.5 \mathrm{~mm}$ to $4 \mathrm{~mm}$ and $0.25 \mathrm{~mm}$ to $1 \mathrm{~mm}$ respectively.

height), however, increases in normalized freeze time obtained by varying pattern spacing or height are small relative to the noise in the measurement. An example time-lapse movie of a droplet test is provided in the supplemental material.

\section{DISCUSSION}

\section{Limitations of ice formation test}

The ice formation test of (Denny et al., 2011) is intended as a simple screening test. Tests in a $-20^{\circ} \mathrm{C}$ freezer may provide an overly large degree of supercooling compared to natural conditions. Another potential limitation is the presence of airborne ice crystals in many walk-in freezers that could nucleate exposed water independent of the organism or sample. Use of dry air, or placement of the $-20^{\circ} \mathrm{C}$ freezer within a $1{ }^{\circ} \mathrm{C}$ freezer, may reduce airborne ice crystals. In the work here, samples were placed away from overhead fans and were partially shielded by cardboard to the sides and above; in future work the method

Table 1. Ice formation test (see Figure 2(a)) of sample plates, time to initial ice formation on samples (mean \pm 2 s.e.) and wetted area for submerged sample plates, $n=13$ sample plates for each texture. Freeze time does not depend on wetted area (linear regression, $P=0.223$ ). Artificial seawater controls did not exhibit submerged ice formation.

\begin{tabular}{rcc}
\hline texture & freeze time, $\mathrm{s}$ & area, $\mathrm{mm}^{2}$ \\
\hline grid & $375 \pm 26$ & 1800 \\
valley & $388 \pm 22$ & 1290 \\
cone & $433 \pm 20$ & 1030 \\
stripes & $465 \pm 22$ & 1520 \\
\hline
\end{tabular}




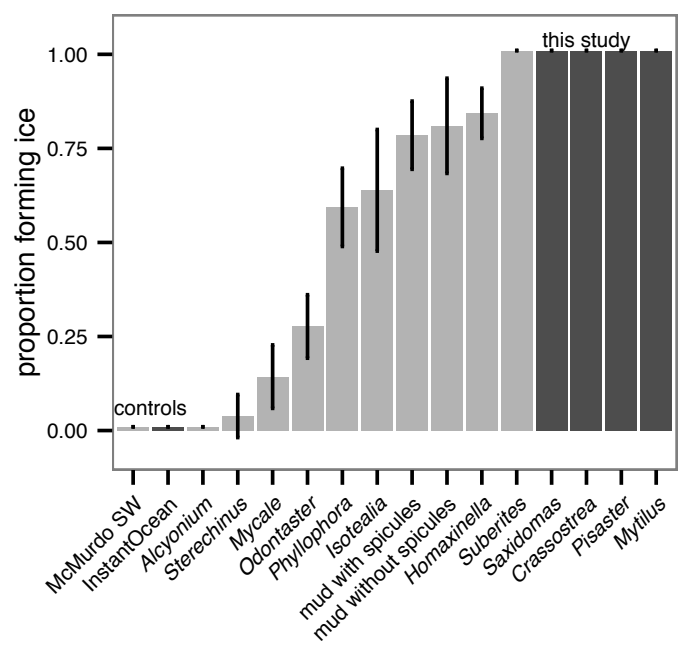

Figure 3. Ice formation test of sub-polar organisms (Saxidomas nuttalli, Crassostrea gigas, Pisaster ochraceus, and Mytilus edulis, dark gray) and artificial seawater control compared to Antarctic data and McMurdo seawater control reproduced from (Denny et al., 2011, figure 3, light gray). All sub-polar samples tested here initiated ice formation prior to completion of the ice formation test ( $n=3$ replicates, with 5 beakers in each replicate). Bars indicate mean \pm 2 s.e.

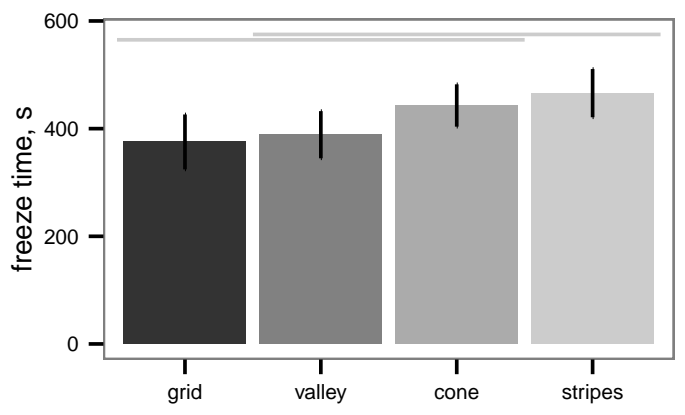

Figure 4. Ice formation test (see Figure 2(a)) of sample plates, time to initial ice formation on samples (mean \pm 2 s.e.), $n=13$ sample plates for each texture. Differences between textures are significant (ANOVA, $P=0.019$ ); light grey lines indicate groups from post-hoc Tukey analysis. Artificial seawater controls in empty beakers did not exhibit submerged ice formation. 


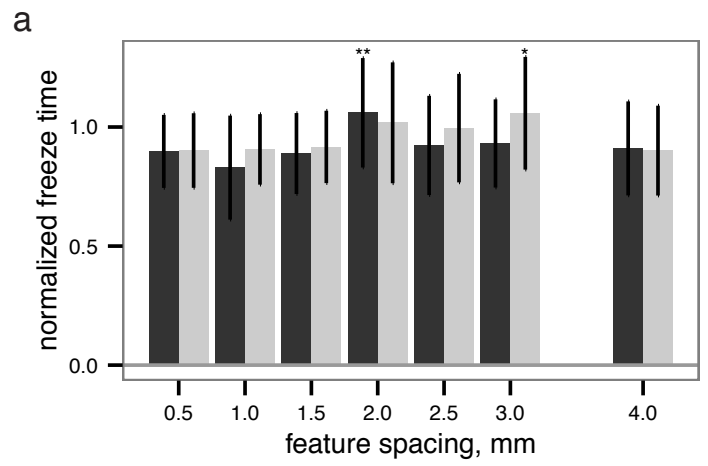

b

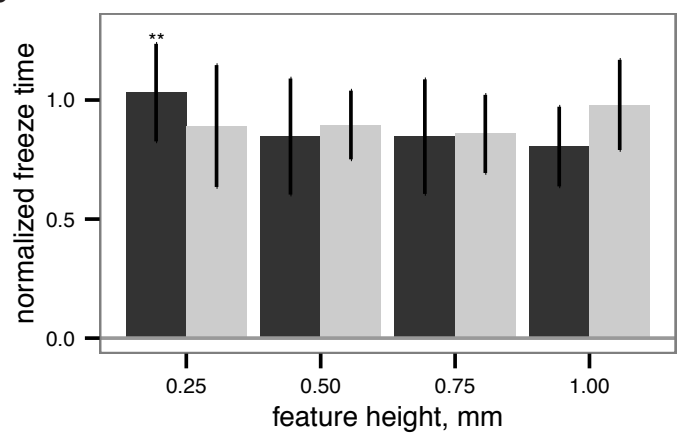

Figure 5. Droplet test (see Figure 2(b-c)), freeze time normalized to mean of flat plate controls versus (a) feature spacing ( $n=45$ droplets) and (b) feature height ( $n=40$ droplets for grid, $n=45$ for stripes), examining sensitivity to surface parameters for two different textures. Grid texture in dark grey; stripes texture in light grey as in Figure 4. Maxima indicated by * for stripes and ** for grid; normalized freeze time does depend on surface parameters (ANOVA, $P=0.0004$ for spacing, $P=0.0389$ for height), but increases in freeze time are small relative to the noise in the measurement. Bars indicate mean \pm 2 s.e.; for flat plate controls, the mean freeze time was $834 \mathrm{~s}$. 
may be improved by use of covers placed over each sample. As some amount of ice always forms on the

surface, this may partially shield the sample from airborne ice. Adding temperature instrumentation may be useful. The droplet test here is also subject to such concerns. We enthusiastically recommend use of controls in the ice formation or droplet tests, and also suggest follow-up with alternative experimental designs that avoid the risk of airborne ice crystals, such as the single ice crystal chamber of (Denny et al., 2011) or an in-situ field manipulation using portable refrigeration coils or supercooled brine injection (Cartwright et al., 2013) to manipulate the local environment.

\section{Sub-polar species always initiated ice formation}

It is perhaps not a surprise that the four species tested (Saxidomas nuttalli, Crassostrea gigas, Pisaster ochraceus, and Mytilus edulis) all initiated ice formation (Figure 3). Although all are found in cold water ( $S$. nuttalli, P. ochraceus, and C. gigas range to Alaska), they are not particularly noteworthy as polar species. On the other hand, hard shelled bivalves of closely-related species can be major components of Arctic communities (Dayton et al., 1994; Gutt, 2001), while echinoderms (e.g. Odontaster and Sterechinus) are hugely important in the Antarctic (Dayton et al., 1969, 1994). The relative ease with which the sub-polar species here initiated ice formation, compared to Antarctic species reported in (Denny et al., 2011), suggests one potential barrier to polar spread: even mild anchor ice events would likely remove all of the sub-polar species we tested. While M. edulis is tolerant of being frozen in ice (Aarset, 1982; Aunaas, 1985; Kanwisher, 1955), (Gutt, 2001) notes that buoyancy effects of ice can cause removal, thus highlighting potential ecomechanical effects of ice formation. While (Denny et al., 2011) did not test mollusks and does not provide direct comparison, the differences we observed between Odontaster, an Antarctic sea star, and P. ochraceus, a sub-polar sea star, which are superficially similar in shape and texture, are suggestive of some other mechanism (perhaps surface material properties, behavior, or the function of cilia). For future work, it may be worthwhile to more systematically probe closely-related pairs with polar versus sub-polar distribution.

\section{Implications for device design}

Contrary to what we hypothesized, simple surface texture does not appear to be a magic bullet able to confer a large degree of ice resistance (Figures 4 and 5). However, careful application of a correctly-spaced texture appears to delay the onset of freezing a small amount, though the mechanism is unclear. For droplet tests in air, one mechanism that may explain the observed maxima is the interaction between hydrophobicity conferred by finely spaced textures (Cassie and Baxter, 1944) and insulation from entrained air within the texture. While our tests did not include measurement of contact angles, the ratio of pattern ping used in our tests corresponded to the region where surface patterning can increase apparent contact angle (Cassie and Baxter, 1944), potentially increasing the thermal insulation provided by trapped air on one side of the drop compared to thermal conduction through the features. However, such a mechanism and its interaction with thermal conduction is uncertain since the minima in these noisy data fall at intermediate spacing and low height. Biologically, while a Cassie wetting mechanism cannot explain subtidal differences as observed in (Denny et al., 2011), it could be relevant in the feather or fur coats of animals, in the intertidal, or in trichomes on leaves, perhaps causing extracorporeal ice nucleation as a means to provide insulation to more sensitive tissues beneath (Duman et al., 1991).

Surface chemistry may have effects on ice resistance; hydrophilic materials reduce resistance to ice adhesion (Meuler et al., 2010a,b) in air, and many biological materials (notably calcium carbonate in bivalve shells and echinoderm ossicles and spines) are hydrophilic. It is unclear what the effect of surface chemistry is in subtidal situations, and the ice resistance of Sterechinus and Odontaster (both echinoderms with calcareous ossicles) appears contrary to expectations from surface chemistry alone. In the echinoderms, the presence of a viscoelastic epithelial covering, potentially with actively moving cilia or mucus secretions, may be key.

\section{Texture has demonstrable, but small, effects on freezing time}

While texture does have demonstrable effects on freezing time, the effects are small (Figures 4 and 5). Mechanical patterning alone cannot explain the large inter-specific differences in ice formation observed in (Denny et al., 2011) for Antarctic species, or the ease with which sub-polar species appear to initiate ice formation. Thus, we infer that the differences observed by (Denny et al., 2011) are due to other effects 
Further dimensions that may be exploited in biological systems but were not examined here include surface wetting (hydrophobic/hydrophilic); surfactants, mucus and slime (as in Mycale); and elastic and viscoelastic properties (e.g. rubbery Alcyonium); nanoscale pattern, multi-scale shape and behavior (e.g. possible changes in behavior or cilia inactivation in sub-polar species held below $-2{ }^{\circ} \mathrm{C}$ ). In an engineering system, these would increase cost; however, perhaps a subset of these may provide synergistic effects resulting in performance improvement in excess of the cost increase. For example, the combination of rigid and viscoelastic materials in a micro-scale composite artificial shark skin was effective in drag reduction (Wen et al., 2014); similar benefits may be attained by mimicking the presence of hard ossicles in a viscous epithelium in certain echinoderms. For ice retardant devices, clearly mechanical designs patterned solely on sub-polar species have not yet provided performance of the same level as the actual polar organisms. Additional observation is needed of multi-scale shape, behavior, and the material properties of perishable tissue and secretions that do not preserve well. Further investigation of ice biology in the field, to examine biomechanical performance in natural environments, along with innovative pairing of materials may enable more effective anti-ice engineering solutions.

\section{ACKNOWLEDGEMENTS}

We thank T Libby and the Berkeley Center for Integrative Biomechanics Education and Research (CIBER); A Doban for use of $\mathrm{a}-20^{\circ} \mathrm{C}$ freezer for testing of devices; E Kepkep for providing invertebrate samples; and R Dudley and T Hedrick for their support. We thank three anonymous reviewers and P Cziko for comments which improved the manuscript. This work was supported by the UC Berkeley Undergraduate Research Apprenticeship Program (URAP).

\section{REFERENCES}

Aarset, A. V. (1982). Freezing tolerance in intertidal invertebrates. Comp Biochem Physiol, 73A:571-580.

Aunaas, T. (1985). Nucleating agents in the haemolymph of an intertidal mollusk tolerant to freezing. Experientia, 38:1456-1457.

230 Carrington, E. (2002). The ecomechanics of mussel attachment: from molecules to ecosystems. Integrative and Comparative Biology, 42:846-852.

Cartwright, J., Escribano, B., González, D., Sainz-Díaz, I., and Tuval, I. (2013). Brincles as a case of inverse chemical gardens. Langmuir, 29:7655-7660.

Cassie, A. B. D. and Baxter, S. (1944). Wettability of porous surfaces. Transactions of the Faraday Society, 40:546-551.

Dayton, P. K. (1989). Interdecadal variation in an Antarctic sponge and its predators from oceanographic climate shifts. Science, 245:1484-1486.

Dayton, P. K., Mordida, B. J., and Bacon, F. (1994). Polar marine communities. American Zoologist, 34:90-99.

Dayton, P. K., Robilliard, G. A., and DeVries, A. L. (1969). Anchor ice formation in McMurdo Sound, Antarctica and its biological effects. Science, 163:273-274.

Dayton, P. K., Robilliard, G. A., and Paine, R. A. (1970). Benthic faunal zonation as a result of anchor ice at McMurdo Sound, Antarctica. In Holgate, M. W., editor, Antarctic Ecology, volume 1, pages 244-258. Academic Press, New York.

Denny, M., Dorgan, K., Evangelista, D., Hettinger, A., Leichter, J., Ruder, W., and Tuval, I. (2011). Anchor ice and benthic disturbance in shallow Antarctic waters: interspecific variation in initiation and propagation of ice crystals. Biol. Bull., 221:155-163.

Denny, M. and Gaylord, B. (2010). Marine ecomechanics. Annu Rev Mar Sci, 2:89-114.

Denny, M. and Helmuth, B. (2009). Confronting the physiological bottleneck: a challenge from ecomechanics. Integrative and Comparative Biology, 49:197-201.

Denny, M. and Miller, L. (2006). Jet propulsion in the cold: mechanics of swimming in the Antarctic scallop Adamussium colbecki. J exp Biol, 209:4503-4514.

Duman, J. G., Wu, D. W., Xu, L., Tursman, D., and Olsen, T. M. (1991). Adaptations of insects to subzero temperatures. $Q$ Rev Biol, 66:387-410.

255 Gusta, L., Wisniewski, M., Nesbitt, N., and Gusta, M. L. (2004). The effect of water, sugars, and proteins on the pattern of ice nucleation and propagation in acclimated and non-acclimated canola leaves. Plant Physiology, 135:1642-1653. 
Gutt, J. (2001). On the direct impact of ice on marine benthic communities, a review. Polar Biology, 24:553-564.

Hansman, Jr., R. (1982). Microwave ice prevention system. United States patent 4,365,131.

Hassan, Y., abd El Halim, A. O., Razaqpur, A. G., Bekheet, W., and Farha, M. H. (2002). Effects of runway de-icers on pavement materials and mixes: comparisons with road salt. Journal of Transportation Engineering, 128:385-391.

Kanwisher, J. W. (1955). Freezing in intertidal animals. Biol Bull, 109:56-63.

Mager, S., Smith, I., Kempema, E., Thomson, B., and Leonard, G. (2013). Anchor ice in polar oceans. Progress in Physical Geography, 37:468-483.

Makkonen, L., Laakso, T., Marjaniemi, M., and Finstad, K. J. (2001). Modeling and prevention of ice accretion on wind turbines. Wind Engineering, 25:3-21.

Meuler, A. J., McKinley, G. H., and E, C. R. (2010a). Exploiting topographical texture to impart icephobicity. In ACS Nano 2010, volume 4, pages 7048-7052.

Meuler, A. J., Smith, J. D., Varanasi, K. K., M, M. J., H, M. G., and Cohen, R. E. (2010b). Relationships between water wettability and ice adhesion. In ACS Applied Material Interfaces 2010, volume 2, pages 3100-3110.

Pavlov, S. (2011). Starfish, Oregon coast. http://commons.wikimedia.org/wiki/ Category:Pisaster_ochraceus\#mediaviewer/File: $\% 282 \% 29$ Starfish\%2C_ Oregon_coast.jpg. Accessed 2014-05-21.

Pearse, J. S., McClintock, B., and Bosch, I. (1991). Reproduction of Antarctic marine invertebrates: tempos, modes, and timing. American Zoologist, 31:65-80.

R Core Team (2014). R: A language and environment for statistical computing.

Wainwright, P. and Reilly, S., edity
University of Chicago Press.

Wen, L., Weaver, J. C., and Lauder, G. V. (2014). Biomimetic shark skin: design, fabrication and hydrodynamic function. J exp Biol, 217:1656-1666.

Wisniewski, M., Fuller, M., Glenn, D. M., Gusta, L., Duman, J., and Griffth, M. (2002). Extrinsic ice nucleation in plants: what are the factors involved and can they be manipulated? In $\mathrm{Li}, \mathrm{P}$. H. and Palva, E. T., editors, Plant Cold Hardiness: Gene Regulation and Genetic Engineering, pages 211-222. Kluwer Academic, New York. 


\section{Figure 1}

Biological inspiration and surface fabrication

(a-b) Saxidomas nuttalli and grid texture; (c-d) Crassostra gigas and valley texture, similar to the Antarctic scallop Adamussium colbecki; (e-f) Pisaster ochraceus (Pavlov, 2011) and cone texture, similar to the Antarctic starfish Odontaster validus; (g-h) Crassostrea gigas and striped texture, similar to the patterning on spines of the Antarctic urchin Sterechinus neumayeri. Photos scaled to approximately $3 \mathrm{~cm}$ width.
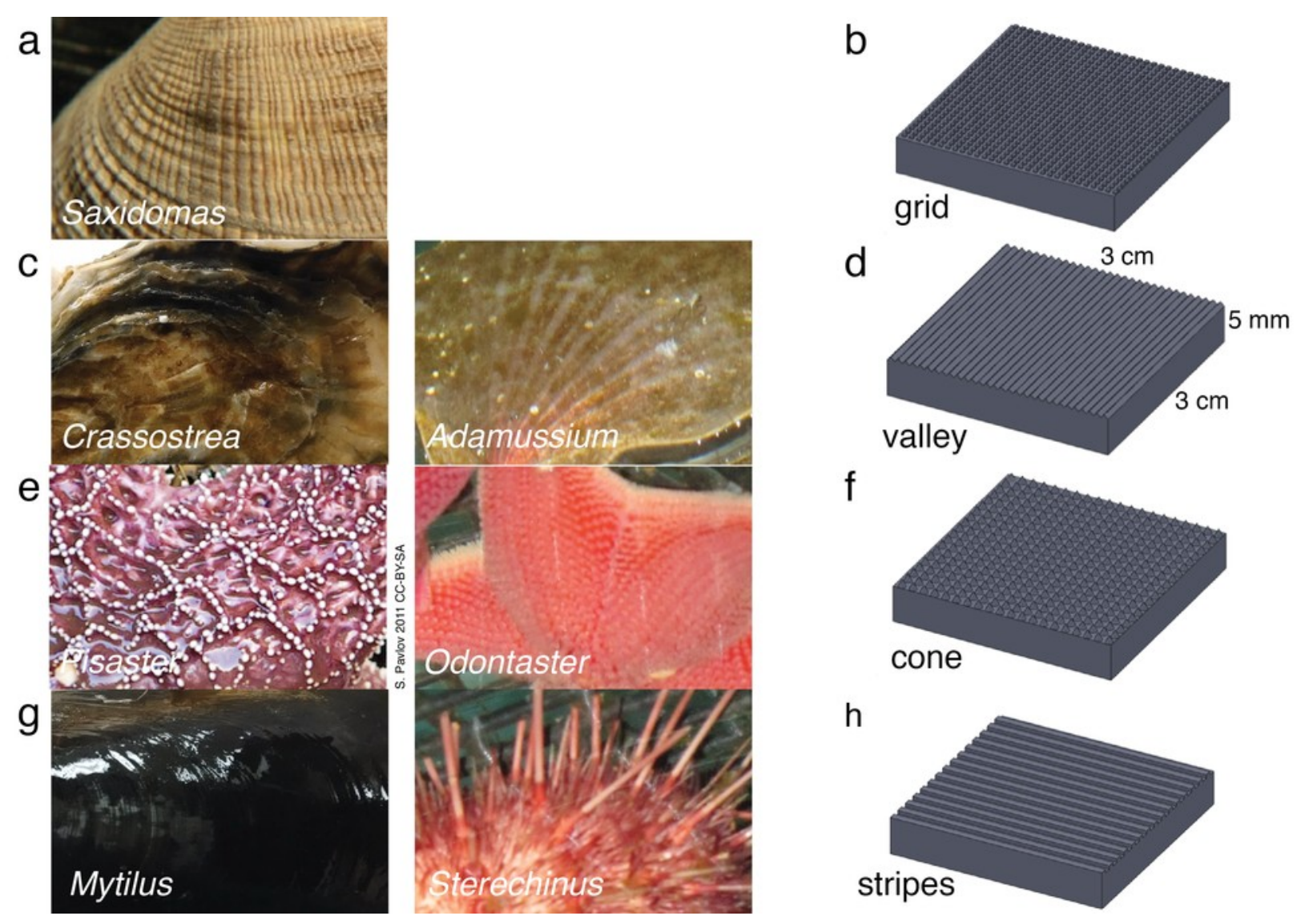


\section{Figure 2}

Ice formation test and droplet test

(a) Submerged ice formation test from (Denny et al., 2011). Plates were placed in $250 \mathrm{~mL}$ beakers and watched for ice formation in a -20 C walk-in freezer. (b) Droplet test to test for ice formation in cold air (intertidal or terrestrial case). Plates and controls were randomly arranged on a tray in the same -20 C freezer. Droplet freezing was identified by color shift from red (middle arrow) to white (upper arrow). Plates $0.03 \mathrm{~m}$ square. (c) Textures and control used during droplet test. Feature width and height varied between $0.5-4 \mathrm{~mm}$ and $0.25-1 \mathrm{~mm}$ respectively. 
a

tripour beaker

submerged plate

b

plates and controls randomly arranged

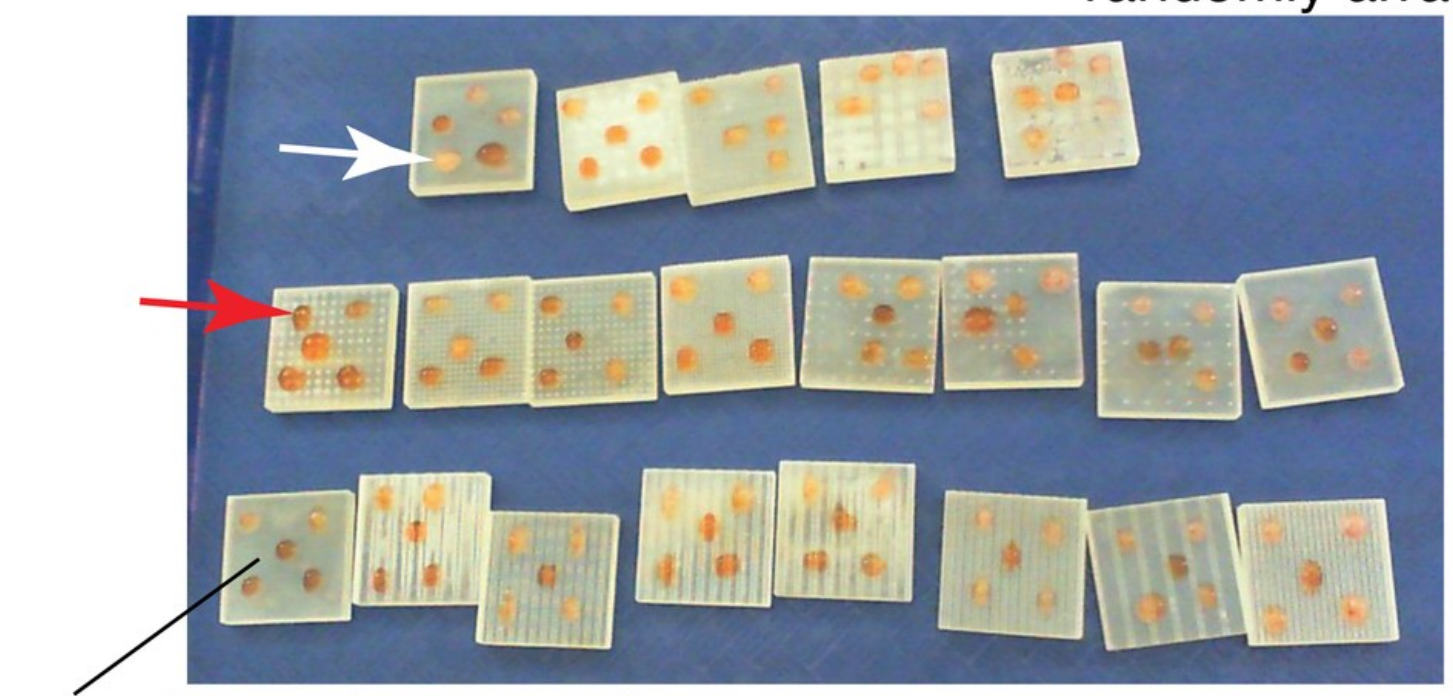

5 replicate drops per plate

C

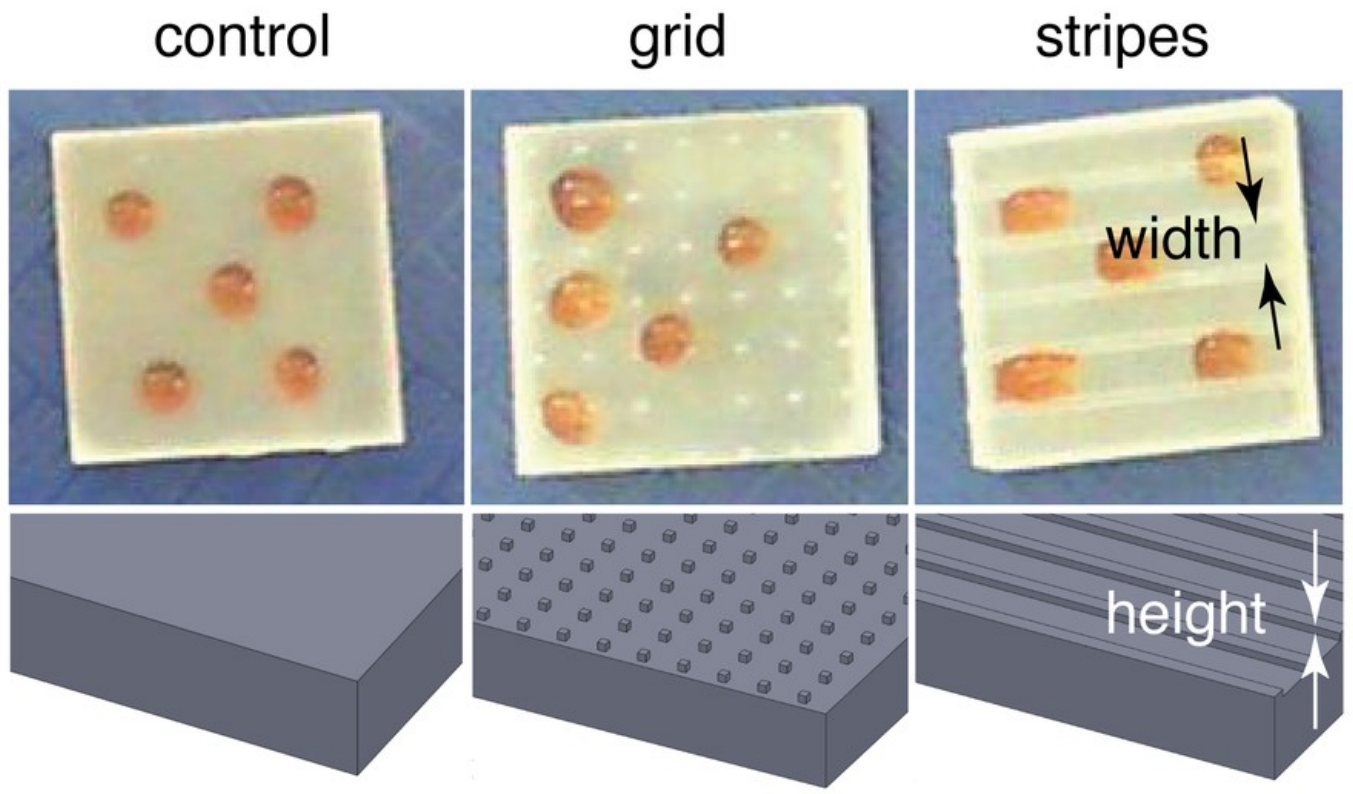




\section{Figure 3}

Ice formation test of sub-polar organisms

Ice formation test of sub-polar organisms (Saxidomas nuttalli, Crassostrea gigas, Pisaster ochraceus, and Mytilus edulis, dark gray) and artificial seawater control compared to Antarctic data and McMurdo seawater control reproduced from (Denny et al. 2011, figure 3, light gray). All sub-polar samples tested here initiated ice formation prior to completion of the ice formation test ( $n=3$ replicates, with 5 beakers in each replicate). Bars indicate mean $+/-2$ s.e. 


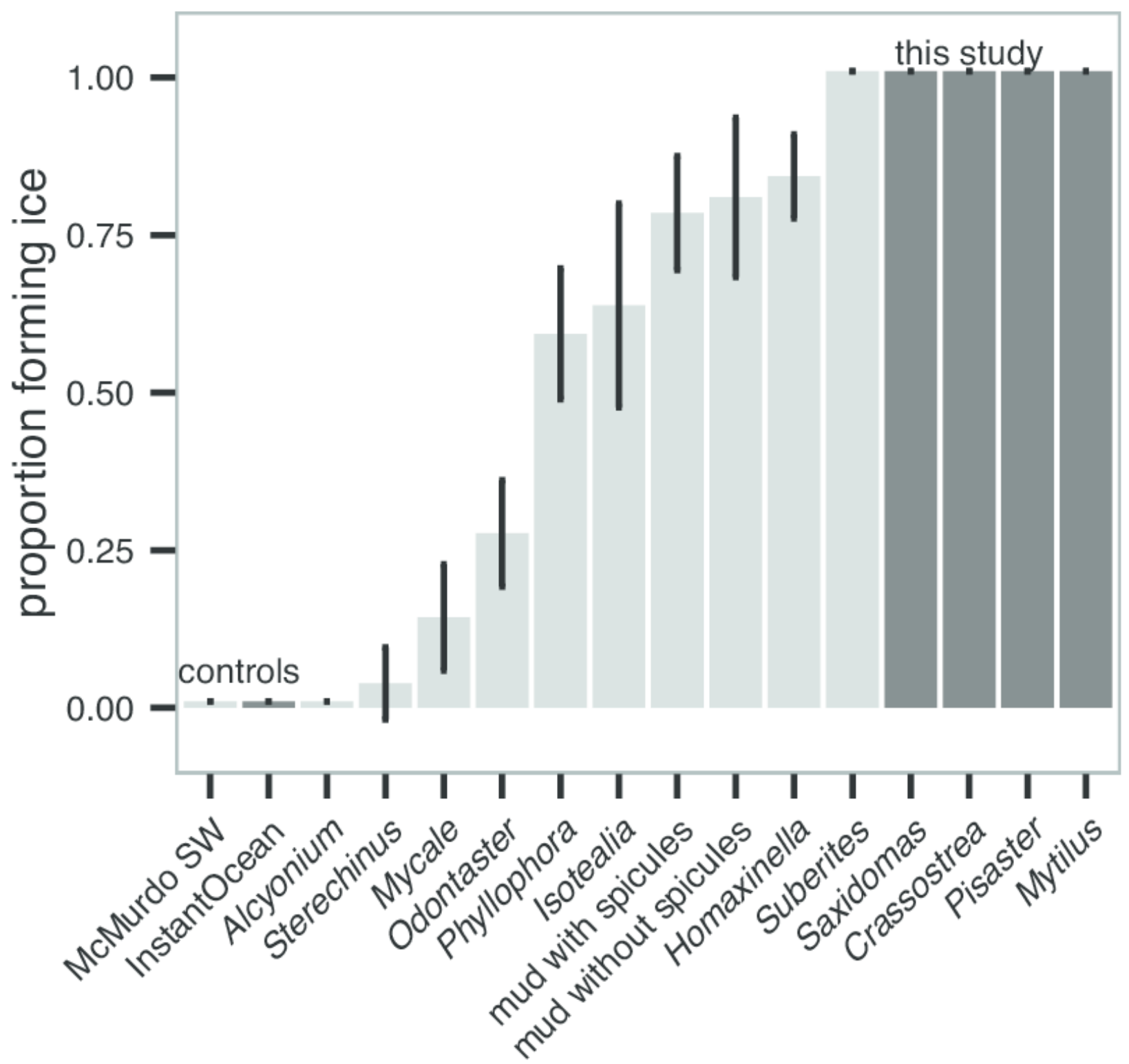




\section{Figure 4}

Ice formation test of sample plates

Ice formation test (see Figure 2(a)) of sample plates, time to initial ice formation on samples (mean $+/-2$ s.e.), $n=13$ sample plates for each texture. Differences between textures are significant (ANOVA, $P=0.019$ ); light grey lines indicate groups from post-hoc Tukey analysis. Artificial seawater controls in empty beakers did not exhibit submerged ice formation.

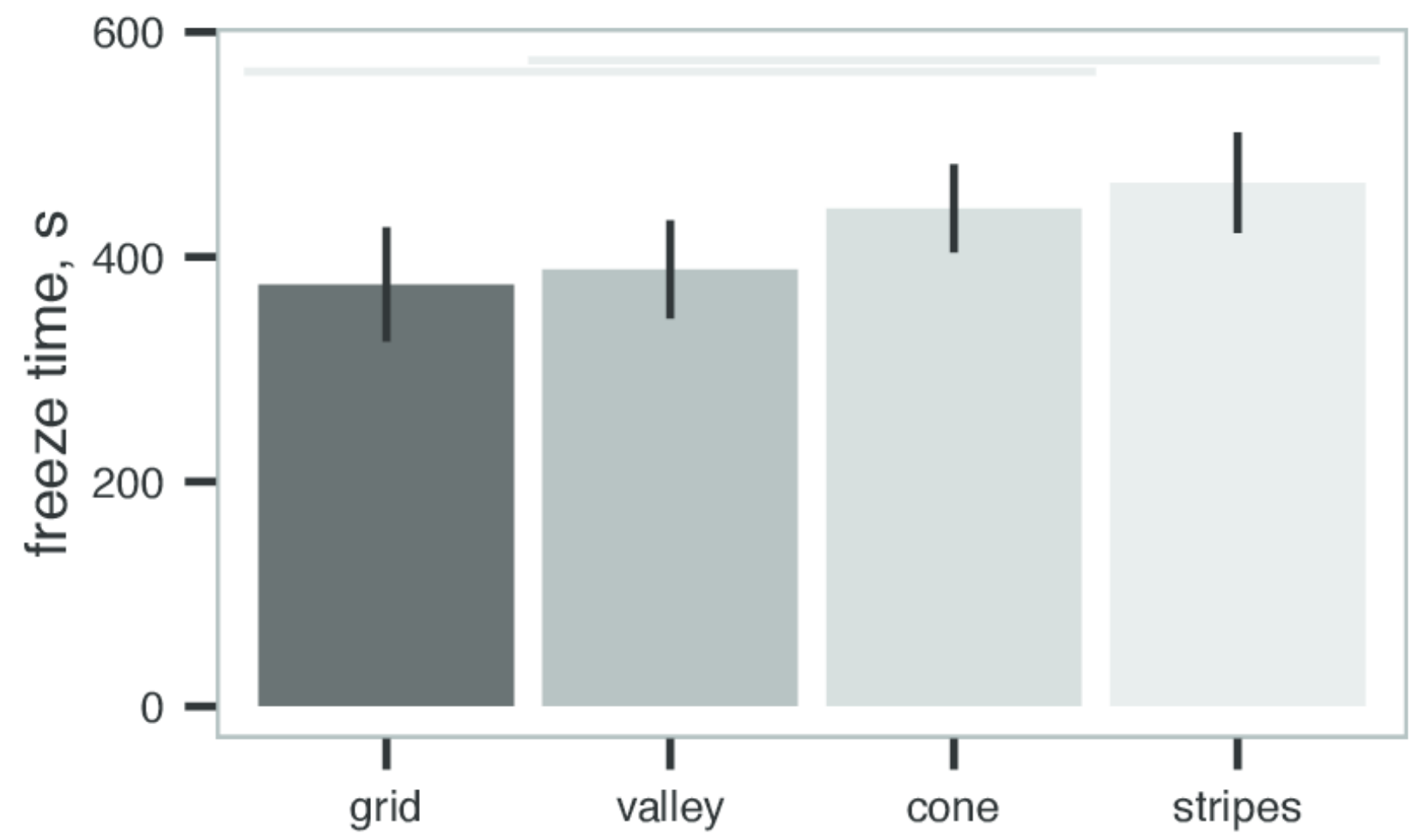




\section{Table $\mathbf{1}_{\text {(on next page) }}$}

Ice formation test of sample plates

Ice formation test (see Figure 2(a)) of sample plates, time to initial ice formation on samples (mean $+/-2$ s.e.) and wetted area for submerged sample plates, $n=13$ sample plates for each texture. Freeze time does not depend on wetted area (linear regression, $P=0.223$ ). Artificial seawater controls did not exhibit submerged ice formation. 


\begin{tabular}{rcc}
\hline texture & freeze time, s & area, $\mathrm{mm}^{2}$ \\
\hline grid & $375 \pm 26$ & 1800 \\
valley & $388 \pm 22$ & 1290 \\
cone & $433 \pm 20$ & 1030 \\
stripes & $465 \pm 22$ & 1520 \\
\hline
\end{tabular}




\section{Figure 5}

Droplet test

Droplet test (see Figure 2(b-c)), normalized freeze time versus (a) feature spacing $(n=45$ droplets) and (b) feature height ( $n=40$ droplets for grid, $n=45$ for stripes), examining sensitivity to surface parameters for two different textures. Grid texture in dark grey; stripes texture in light grey as in Figure 4. Maxima indicated by * for stripes and ** for grid; normalized freeze time does depend on surface parameters (ANOVA, $P=0.0004$ for spacing, $P=0.0389$ for height), but increases in freeze time are small relative to the noise in the measurement. Bars indicate mean +/- 2 s.e.; for flat plate controls, the mean freeze time was $834 \mathrm{~s}$. 
a

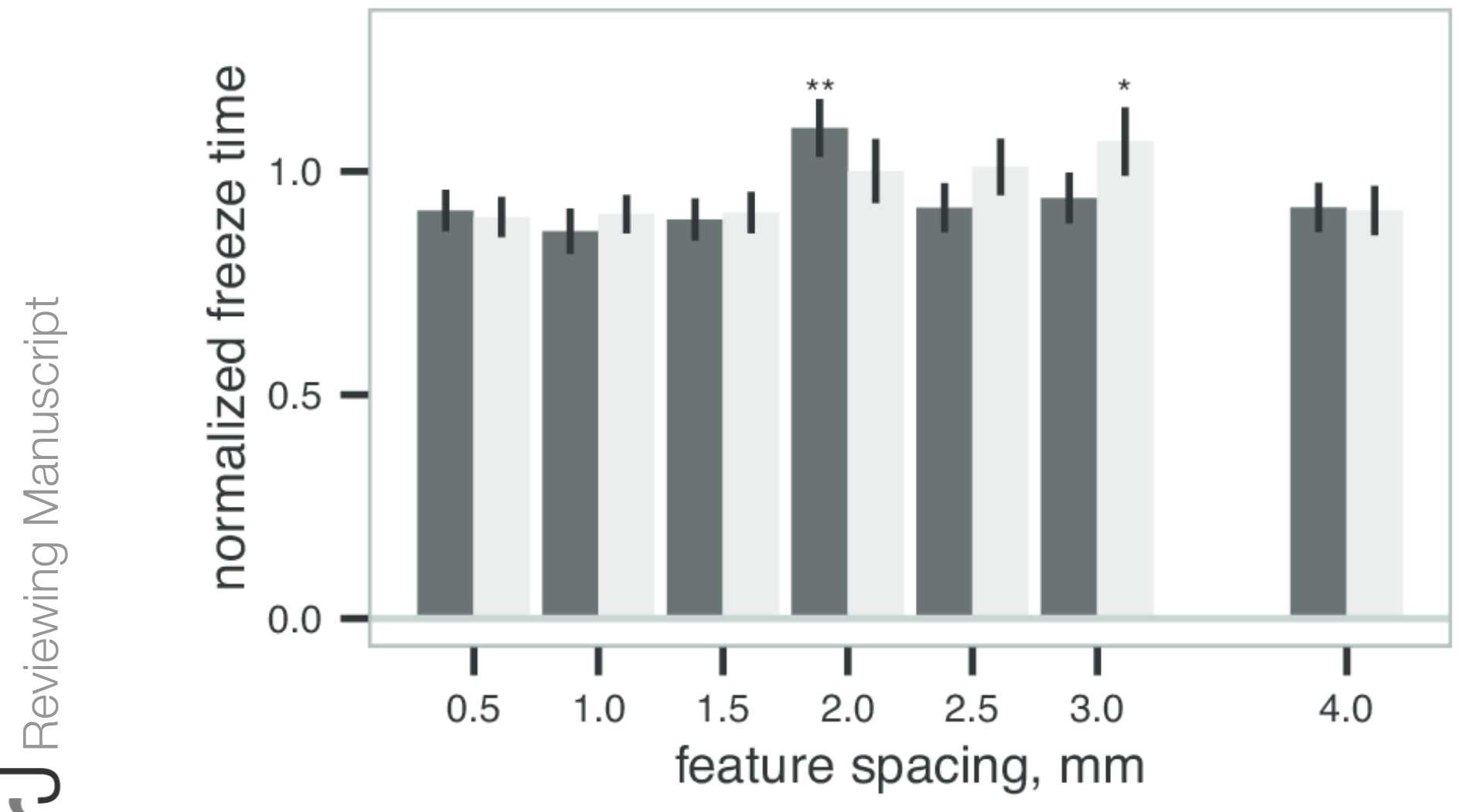

b

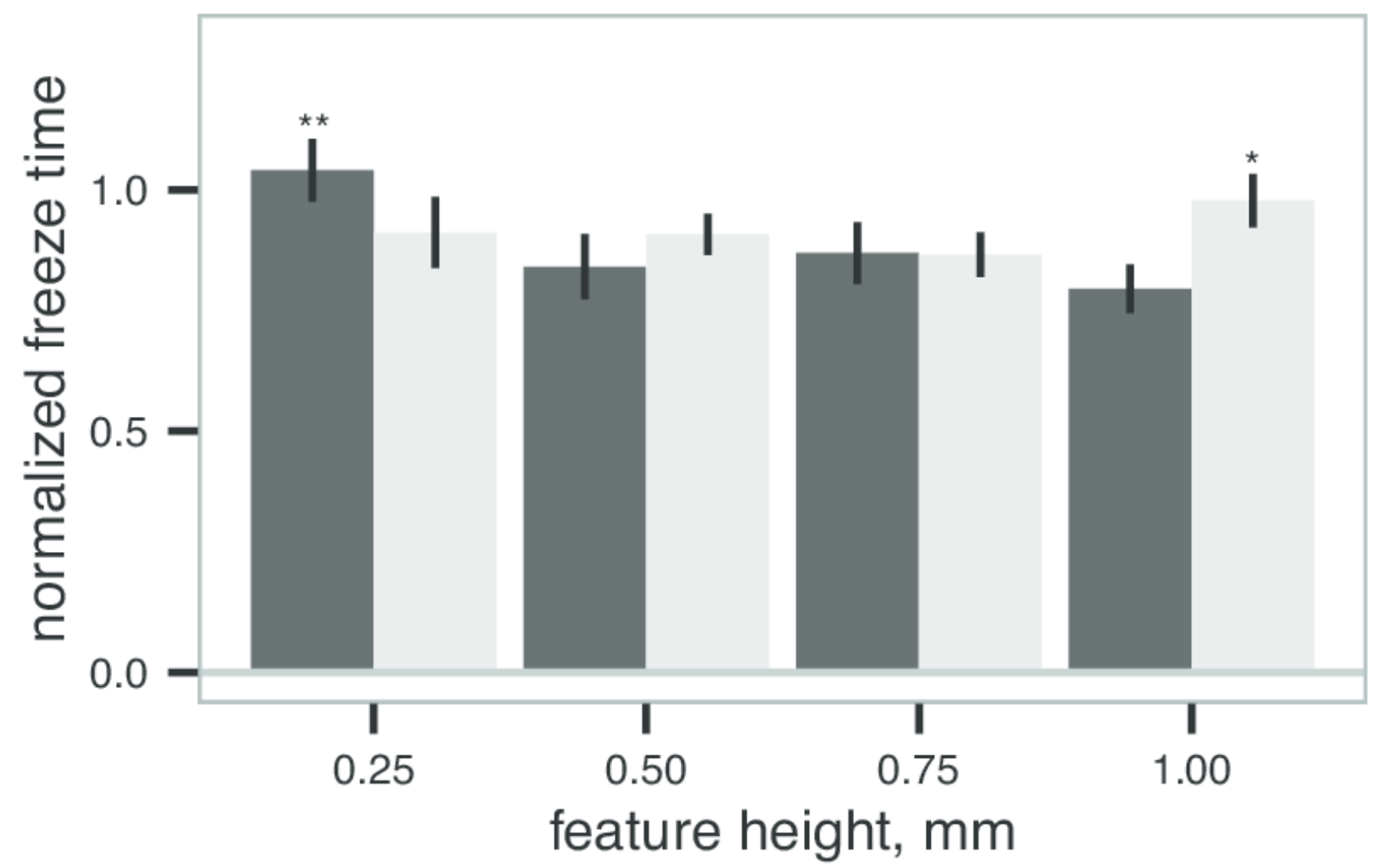

